\title{
A falsa dicotomia entre a preservação da vegetação natural e a produção agropecuária
}

\author{
Luiz Antonio Martinelli ${ }^{1,2,6}$, Carlos Alfredo Joly ${ }^{3}$, Carlos Afonso Nobre ${ }^{4}$ \& Gerd Sparovek ${ }^{5}$ \\ ${ }^{1}$ Centro de Energia Nuclear na Agricultura, Universidade de São Paulo - USP, \\ Av. Centenário, n. 303, CEP 13416-000, Piracicaba, SP, Brasil \\ ${ }^{2}$ Fellow Program on Food Security and the Environment, Stanford University, USA \\ ${ }^{3}$ Departamento de Biologia Vegetal, Universidade Estadual de Campinas - UNICAMP, \\ Barão Geraldo, CEP 13081-970, Campinas, SP, Brasil \\ ${ }^{4}$ Instituto Nacional de Pesquisas Espaciais, Centro de Ciência do Sistema Terrestre, \\ Av. dos Astronautas, n. 1758, Jardim da Granja, CEP 12227-010, São José dos Campos, SP, Brasil \\ ${ }^{5}$ Departamento de Ciência do Solo, Escola Superior de Agricultura "Luiz de Queiróz", \\ Av. Pádua Dias, n. 11, CEP 13416-000, Piracicaba, SP, Brasil \\ ${ }^{6}$ Autor para correspondência: Luiz,Antonio Martinelli,e-mail: martinelli@cena.usp.br
}

\begin{abstract}
MARTINELLI, L.A., JOLY, C.A., NOBRE, C.A. \& SPAROVEK, G. The false dichotomy between preservation of the natural vegetation and food production in Brazil. Biota Neotrop. 10(4): http://www.biotaneotropica. org.br/v10n4/en/abstract?point-of-view+bn00110042010.
\end{abstract}

\begin{abstract}
Through the analysis of census data on land use in Brazil this article shows that the dichotomy between food production and preservation of natural vegetation used as the main driver to change the Forest Code is false. We showed here that Brazil has already cleared an area large enough that support the production of food, fiber and bioenergy to meet the requirements of the country and global markets. We also showed the area of export-oriented crops like soybean and sugar cane have been expanded significantly in the last decades, while staple crops like rice and bean have decreased and the area planted with cassava has been stable for the last four decades. At the same time we show that the productivity of export-oriented crops has increased in a much more significant rate than staple crops or cattle stocking rate, which in average is extremely low in Brazil. We concluded by stating that the real constraint for food production in Brazil does not rely on the Forest Code environmental restrictions but instead in inequalities in land distribution and income, coupled with lack of credit to small producers and investment in research and development in the staples crops of the country.
\end{abstract}

Keywords: food, land use, preservation, environmental law, Brazilian Forest Code.

MARTINELLI, L.A., JOLY, C.A., NOBRE, C.A. \& SPAROVEK, G. A falsa dicotomia entre a preservação da vegetação natural e a produção agropecuária. Biota Neotrop. 10(4): http://www.biotaneotropica.org.br/ v10n4/pt/abstract?point-of-view+bn00110042010.

Resumo: Este artigo mostra através da análise de dados censitários sobre uso da terra no Brasil que a possível dicotomia entre a preservação da vegetação natural e a produção de alimentos na realidade não existe. Demonstramos que o Brasil já tem uma área desprovida de vegetação natural suficientemente grande para acomodar a expansão da produção agrícola. Demonstramos também que a maior expansão se dá nas áreas ocupadas pelas chamadas culturas de exportação - soja e cana-de-açúcar - e não propriamente nas áreas ocupadas por arroz, feijão e mandioca, que são consumidos de forma direta pelo mercado nacional. Pelo contrário, a área colhida de arroz e feijão tem inclusive decrescido nas últimas décadas, enquanto a área colhida de mandioca encontra-se praticamente constante há quatro décadas. Os maiores entraves para a produção de alimentos no Brasil não se devem a restrições supostamente impostas pelo Código Florestal, mas, sim, à enorme desigualdade na distribuição de terras, a restrição de crédito agrícola ao agricultor que produz alimentos de consumo direto, a falta de assistência técnica que o ajude a aumentar a sua produtividade, a falta de investimentos em infraestrutura para armazenamento e escoamento da produção agrícola, a restrições de financiamento e priorização do desenvolvimento e tecnologia que permita um aumento expressivo na lotação de nossas pastagens,

Palavras-chave: alimentos, uso do solo, preservação, leis ambientais, Código Florestal Brasileiro. 


\section{Introdução}

A proposta de reformulação do Código Florestal tem se baseado em vários argumentos. Um deles, defendido pelo Deputado Aldo Rebelo, relator do projeto sobre reformulação do Código ${ }^{1}$, é que as mudanças são necessárias pela ameaça à possibilidade de produção de alimentos. Claramente é colocada a dicotomia: ou preservamos ou produzimos alimentos. Nossa intenção neste artigo é demonstrar que essa dicotomia é falsa e inexiste. O Brasil tem área suficiente para a preservação de nosso patrimônio biológico e para também continuar aumentando a produção de alimentos para o consumo interno e exportações.

Para tal situamos a ocupação das terras brasileiras com agricultura e pecuária em comparação com os Estados Unidos da América (EUA) e o bloco constituído por países da União Europeia² (UE). Esta comparação é interessante, pois o Brasil, os EUA e a UE estão entre os mais importantes exportadores de produtos agropecuários do mundo. Em segundo lugar, iremos mostrar a variação de 1961 até 2008 na área colhida e na produtividade de dois conjuntos de culturas agrícolas: aquelas destinadas em elevada proporção à exportação (soja e a cana-de-açúcar) ou que ocupam uma grande área (milho) e aquelas que são destinadas basicamente à alimentação direta no mercado nacional (arroz, feijão e mandioca). Incluímos também nesta análise a evolução da pecuária produzida a pasto durante o mesmo período pela importância que esta atividade tem no Brasil tanto economicamente como em termos da grande área que ocupa. Finalmente, comparamos a produtividade de algumas culturas agrícolas importantes com outros países.

\section{Material e Métodos}

A maior parte dos dados utilizados neste artigo provém da base de dados da Organização das Nações Unidas para Agricultura e Alimentação (FAO) e foram obtidos através do seguinte endereço: www.faostat.org (FAOSTAT 2010). Os dados sobre produtividade nas regiões geográficas do país e sobre a distribuição de terras foram obtidas junto ao SIDRA, que é o banco de dados agropecuários do
IBGE (2010) (www.sidra.ibge.gov.br). Para se relacionar o número de propriedades com o tamanho das propriedades utilizou-se informações obtidas junto ao SIDRA e a Tabela 1 exemplifica o tipo de dados obtidos. A coluna A da Tabela 1 mostra as classes de tamanho de propriedades definidas pelo SIDRA. A cada classe de tamanho de propriedade, encontra-se associado um determinado número de propriedades (coluna B) e a área englobada por aquela classe de tamanho da propriedade (coluna C). Estes valores são transformados em percentuais em relação ao número total de propriedades e a área total das propriedades (últimas linhas das colunas B e C) e são visualizados nas colunas D e E). Finalmente, as colunas F e G mostram a soma acumulada das propriedades e das áreas, respectivamente. Com essas duas últimas variáveis constrói-se o gráfico de distribuição das terras em função do tamanho das propriedades, que demonstra claramente elevada concentração de sua posse. Quanto mais a linha se afasta de uma relação 1:1, maior será a desigualdade.

Para relacionar o tamanho das propriedades com a área colhida de arroz, feijão, mandioca, milho, cana-de-açúcar e soja, utilizaram-se informações obtidas junto ao SIDRA e a Tabela 2 exemplifica o tipo de dados obtidos. A coluna A da Tabela 2 mostra as classes de tamanho de propriedades definidas pelo SIDRA. A coluna B mostra o limite inferior de cada classe de área das propriedades. A coluna $C$ é o valor acumulado desses limites inferiores das classes. As colunas D e E são as áreas colhidas da cultura em questão expressas em hectare e em percentual em relação a área total colhida que encontra-se na última linha da coluna D. Finalmente a coluna F é a área colhida acumulada e o gráfico a ser produzido terá na ordenada o limite inferior acumulado e na abscissa a área colhida acumulada. Como não há uma definição do limite superior da última classe de área ("De 2500 ha e mais"), não é possível estabelecer o limite real que seria aquele correspondente às maiores propriedades do país. Como não se tem esse limite, o limite acumulado produziu na última linha desta coluna (coluna $\mathrm{C}$ ) o valor de aproximadamente 4395 ha, que é um valor hipotético e utilizado para fins gráficos, mas não é um valor real, pois obviamente existem propriedades com área maior que este valor.

Tabela 1. Dados utilizados para elaboração da Figura 5 sobre a desigualdade na distribuição de terras no Brasil.

Table 1. Data source about land distribution inequality used to elaborate Figure 5.

\begin{tabular}{|c|c|c|c|c|c|c|}
\hline $\mathbf{A}$ & $\mathbf{B}$ & $\mathbf{C}$ & $\mathbf{D}$ & $\mathbf{E}$ & $\mathbf{F}$ & $\mathbf{G}$ \\
\hline $\begin{array}{c}\text { Classes de área de } \\
\text { propriedades }\end{array}$ & Propriedades & $\begin{array}{l}\text { Área } \\
\text { (ha) }\end{array}$ & $\begin{array}{c}\text { Propriedades } \\
(\%)\end{array}$ & $\begin{array}{c}\text { Áreas } \\
(\%)\end{array}$ & $\begin{array}{c}\text { Propriedades cumulativo } \\
(\%)\end{array}$ & $\begin{array}{c}\text { Área cumulativa } \\
(\%)\end{array}$ \\
\hline Menos de 0,1 ha & 101287 & 3749 & 2.06 & 0.00 & 2.06 & 0.00 \\
\hline De 0,1 a menos de 0,2 ha & 50194 & 7037 & 1.02 & 0.00 & 3.08 & 0.00 \\
\hline De 0,2 a menos de 0,5 ha & 165434 & 55028 & 3.36 & 0.02 & 6.44 & 0.02 \\
\hline De 0,5 a menos de 1 ha & 289893 & 199005 & 5.89 & 0.06 & 12.33 & 0.08 \\
\hline De 1 a menos de 2 ha & 442148 & 563880 & 8.99 & 0.17 & 21.32 & 0.25 \\
\hline De 2 a menos de 3 ha & 319656 & 711113 & 6.50 & 0.22 & 27.81 & 0.47 \\
\hline De 3 a menos de 4 ha & 256145 & 826217 & 5.21 & 0.25 & 33.02 & 0.72 \\
\hline De 4 a menos de 5 ha & 215977 & 947732 & 4.39 & 0.29 & 37.41 & 1.00 \\
\hline De 5 a menos de 10 ha & 636337 & 4484847 & 12.93 & 1.36 & 50.34 & 2.36 \\
\hline De 10 a menos de 20 ha & 736792 & 10289684 & 14.97 & 3.12 & 65.32 & 5.48 \\
\hline De 20 a menos de 50 ha & 843911 & 26120628 & 17.15 & 7.92 & 82.47 & 13.40 \\
\hline De 50 a menos de 100 ha & 390874 & 26482780 & 7.94 & 8.03 & 90.41 & 21.43 \\
\hline De 100 a menos de 200 ha & 220255 & 29342738 & 4.48 & 8.89 & 94.89 & 30.32 \\
\hline De 200 a menos de 500 ha & 150859 & 46395555 & 3.07 & 14.06 & 97.95 & 44.38 \\
\hline De 500 a menos de 1000 ha & 53792 & 36958185 & 1.09 & 11.20 & 99.05 & 55.58 \\
\hline De 1000 a menos de 2500 ha & 31899 & 48072546 & 0.65 & 14.57 & 99.69 & 70.15 \\
\hline De 2500 ha e mais & 15012 & 98480672 & 0.31 & 29.85 & 100.00 & 100.00 \\
\hline Total & 4920465 & 329941396 & - & - & - & - \\
\hline
\end{tabular}

Fonte de dados: www.sidra.ibge.br, Tabela 837 - http://www.sidra.ibge.gov.br/bda/tabela/listabl.asp?c=837\&z=t\&o=11. 
Tabela 2. Dados utilizados para elaboração da Figura 6 sobre o tamanho das propriedades e área colhida de várias culturas. Neste exemplo, apresenta-se os dados referentes ao cultivo da soja no Brasil.

Table 2. Data source on rural properties areas and harvested areas os several crops used to elaborate Figure 6. In this example data are related to soybeans.

\begin{tabular}{|c|c|c|c|c|c|}
\hline $\mathbf{A}$ & B & $\mathbf{C}$ & D & $\mathbf{E}$ & $\mathbf{F}$ \\
\hline $\begin{array}{c}\text { Classes de áreas das } \\
\text { propriedades }\end{array}$ & $\begin{array}{c}\text { Limite inferior } \\
\text { (ha) }\end{array}$ & $\begin{array}{c}\text { Limite inferior acumulado } \\
\text { (ha) }\end{array}$ & $\begin{array}{l}\text { Área colhida } \\
\text { (ha) }\end{array}$ & $\begin{array}{c}\text { Área colhida } \\
(\%)\end{array}$ & $\begin{array}{c}\text { Área colhida acumulada } \\
(\%)\end{array}$ \\
\hline Mais de 0 a menos de 0,1 ha & 0 & 0 & 36 & 0.00023 & 0.00023 \\
\hline De 0,1 a menos de 0,2 ha & 0.1 & 0.1 & 40 & 0.00026 & 0.00049 \\
\hline De 0,2 a menos de 0,5 ha & 0.2 & 0.3 & 29 & 0.00019 & 0.00067 \\
\hline De 0,5 a menos de 1 ha & 0.5 & 0.8 & 348 & 0.00222 & 0.0029 \\
\hline De 1 a menos de 2 ha & 1 & 1.8 & 3038 & 0.01942 & 0.02231 \\
\hline De 2 a menos de 3 ha & 2 & 3.8 & 8866 & 0.05667 & 0.07898 \\
\hline De 3 a menos de 4 ha & 3 & 6.8 & 19611 & 0.12534 & 0.20432 \\
\hline De 4 a menos de 5 ha & 4 & 10.8 & 45101 & 0.28826 & 0.49258 \\
\hline De 5 a menos de 10 ha & 5 & 15.8 & 203090 & 1.29803 & 1.79061 \\
\hline De 10 a menos de 20 ha & 10 & 25.8 & 586246 & 3.74694 & 5.53756 \\
\hline De 20 a menos de 50 ha & 20 & 45.8 & 1221120 & 7.80469 & 13.3422 \\
\hline De 50 a menos de 100 ha & 50 & 95.8 & 997452 & 6.37513 & 19.7174 \\
\hline De 100 a menos de 200 ha & 100 & 195.8 & 1211314 & 7.74201 & 27.4594 \\
\hline De 200 a menos de 500 ha & 200 & 395.8 & 2163739 & 13.8294 & 41.2888 \\
\hline De 500 a menos de 1000 ha & 500 & 895.8 & 2108623 & 13.4771 & 54.7658 \\
\hline De 1000 a menos de 2500 ha & 1000 & 1895.8 & 2798477 & 17.8862 & 72.6521 \\
\hline De 2500 ha e mais & 2500 & $4395.8 *$ & 4278850 & 27.3479 & 100 \\
\hline
\end{tabular}

Fonte de dados: www.sidra.ibge.br.

\section{Resultados}

\section{Comparações entre o uso da terra no Brasil, Estados Unidos e União Europeia}

A área ocupada com agricultura e pecuária bovina encontra-se em declínio nos EUA e na UE e vem aumentando continuamente no Brasil, onde alcançou cerca de 250 milhões de ha em 2007, contra cerca de 400 milhões de ha nos EUA e cerca de 190 milhões de ha na UE (Figura 1a). Em percentual, esses números indicam que, em relação à área terrestre total do país ou da UE, a agricultura e a pecuária nos EUA e na UE ocupam cerca de $50 \%$, enquanto no Brasil ocupam somente cerca de $30 \%^{3}$ (Figura 1b). Deste total, a maioria é ocupada por pecuária bovina, principalmente nos EUA e no Brasil, havendo um pequeno declínio na área ocupada por pecuária nos EUA e na UE, enquanto houve um aumento contínuo no Brasil, chegando a cerca de 200 milhões, contra cerca de milhões de 70 milhões de ha na UE e 170 milhões de ha nos EUA (dados não mostrados na Figura 1). A área ocupada com agricultura no Brasil vem aumentando nas últimas quatro décadas e atualmente ocupa em torno de 60 milhões de ha. Por outro lado, nota-se um pequeno declínio na área ocupada por agricultura nos EUA e na EU, mas em ambas regiões a área ocupada por esta atividade é significantemente maior que no Brasil, ocupando cerca de 110 e 170 milhões de ha nos EUA e na EU, respectivamente (Figura 1c). Em termos percentuais, a área destinada à agricultura no Brasil equivale somente a 7\% da área total terrestre, subindo para 20 e $30 \%$ nos EUA e UE, respectivamente (Figura 1d). Finalmente, a área coberta com florestas nos EUA e na UE apresentaram pequeno aumento, no Brasil as mesmas encontram-se em declínio (Figura 1e). Em termos percentuais, os diversos tipos de vegetação natural ocupam pouco menos de $40 \%$ nos EUA e na UE, enquanto ocupam 55\% no Brasil (Figura 1f).

\section{2. Área colhida e produtividade de algumas culturas no país}

A área colhida de soja e cana-de-açúcar no Brasil vem aumentando vertiginosamente, enquanto a área de milho se encontra aproximadamente estável em relação às outras duas culturas (Figura 2a). $\mathrm{O}$ aumento da área foi seguido também por um aumento acentuado na produtividade da cana e da soja e também na produtividade do milho (Figura 2b). Por outro lado, a área colhida de mandioca manteve-se praticamente constante nestas últimas cinco décadas, enquanto as áreas colhidas com feijão e arroz entraram em declínio no final dos anos 70 e início dos anos 80 (Figura 2c). Somente para a cultura do arroz foi observado um aumento considerável de produtividade nos últimos 20 anos, enquanto a produtividade de feijão teve um aumento modesto e uma estagnação na produtividade da mandioca (Figura 2d). Finalmente, a área coberta com pastagens aumentou também significativamente nas últimas 4 décadas, atingindo cerca de 200 milhões de ha; sendo que o rebanho bovino brasileiro tem aproximadamente 200 milhões de cabeças, resultando em uma lotação média de aproximadamente uma cabeças por hectare (Figura 3).

\section{A produtividade das culturas brasileiras comparadas àquela de outros países ${ }^{4}$}

A produtividade média de arroz e feijão do Brasil é uma das mais baixas em relação aos países comparados e apenas intermediária para o caso da mandioca (Figura 4a, c). O mesmo ocorre com a produtividade do milho, que apesar da grande área coberta por esta cultura, sua produtividade encontra-se dentre as mais baixas (Figura 4d). No entanto, enfatiza-se que a baixa produtividade desta cultura no Brasil em parte justifica-se pela inclusão de áreas produzidas fora da época ideal como segundo cultivo (safrinha).

Somente a produtividade da soja e da cana, no Brasil, é comparável às produtividades alcançadas nos outros países considerados 
Martinelli, L.A. et al.
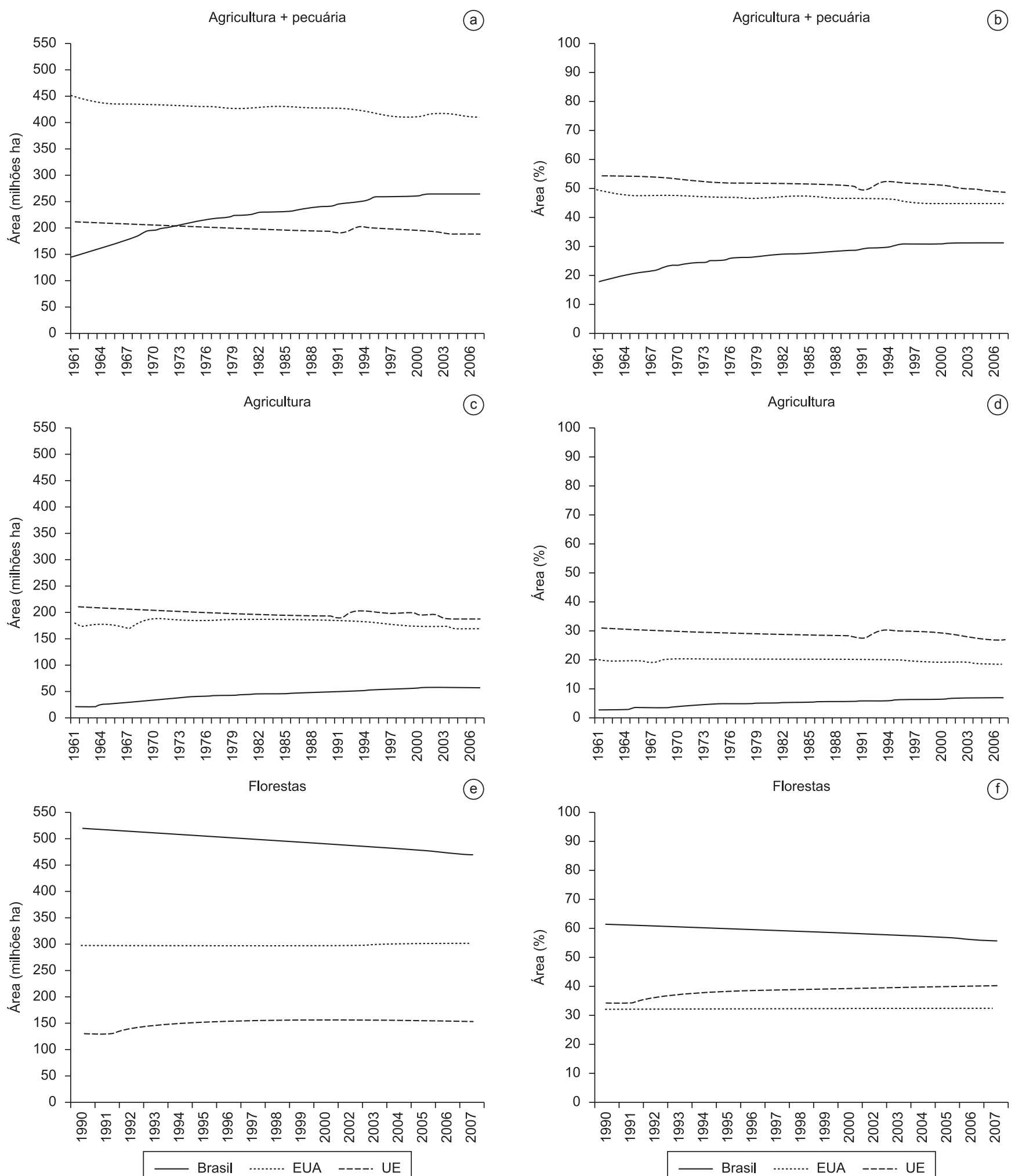

Figura 1. a) Área utilizada pela agricultura e pecuária expressa em milhões de ha; b) percentualmente em relação à área total do Brasil, Estados Unidos e União Europeia; c) área utilizada somente pela agricultura em milhões de hectares; d) percentualmente em relação à área total do Brasil, Estados Unidos e União Europeia; e) Área ocupada por florestas em milhões de ha; f) percentualmente em relação à área total do Brasil, Estados Unidos e União Europeia.

Figure 1. a) Agricultural and cattle livestock areas (million of ha); b) percent in relation to the total area of Brazil, United States, and European Union; c) agricultural area only (million of ha); d) percent in relation to the total area of Brazil, United States and European Union; e) Forest area (million ha); f) percent in relation to the total area of Brazil, United States and European Union. 

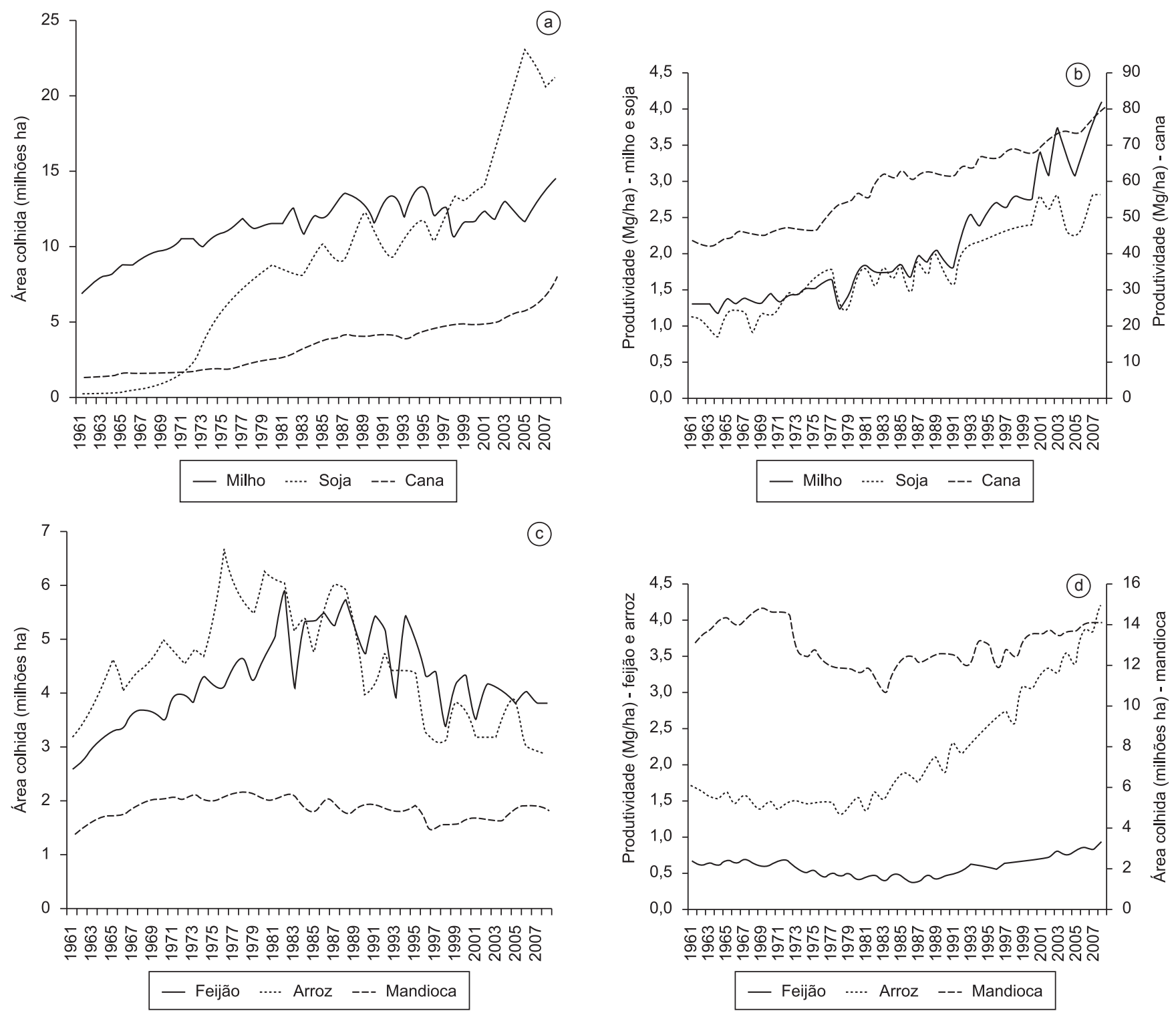

Figura 2. a) Área colhida em milhões de ha; b) produtividade agrícola das culturas de milho, soja e cana-de-açúcar; c) área colhida em milhões de ha; d) produtividade agrícola das culturas feijão, arroz e mandioca.

Figure 2. a) Harvested area (million ha); b) productivity of corn, soybean and sugarcane; c) harvested area (million ha); d) productivity of beans, rice and cassava.

(Figura 4e). Analisando apenas as regiões mais produtivas do país para cada cultura, nota-se uma melhora considerável em comparação a outros países em relação ao arroz, mais produtivo na região sul, provavelmente devido ao fato de nesta região do país predominar o plantio nas várzeas e não arroz de sequeiro; ao feijão, mais produtivo na região centro-oeste, e a mandioca, mais produtiva na região norte do país (Figura 4a, c). No caso do milho, houve pouca diferença entre a produtividade média do país a produtividade média da região geográfica mais produtiva (Figura 4d). As demais culturas, cana e soja, já se encontravam com produtividades comparáveis aos países mais produtivos; mesmo assim, no caso da soja, o Brasil passa a ser o segundo país em produtividade quando consideradas as altas produtividades médias alcançadas na região centro-oeste do país (Figura 4e).

\section{A distribuição de terras no país e a produção agrícola em função dos tamanhos das propriedades}

Utilizando-se os dados da Tabela 1 produziu-se a Figura 5, que mostra haver uma grande desigualdade na distribuição da posse de terras no país. Nota-se um grande afastamento da curva em relação à linha 1:1, a qual representa uma situação hipotética de absoluta igualdade de sua distribuição em relação às classes de tamanho. Outra forma de interpretar este gráfico seria, por exemplo, que cerca de $80 \%$ do número de proprietários detêm somente $20 \%$ da área agrícola do país. É interessante notar que há décadas que esta desigualdade não muda, apesar do país ser um dos únicos países do mundo que mantém um expressivo programa de Reforma Agrária, combinando mecanismos públicos (desapropriação, aquisição pelo 


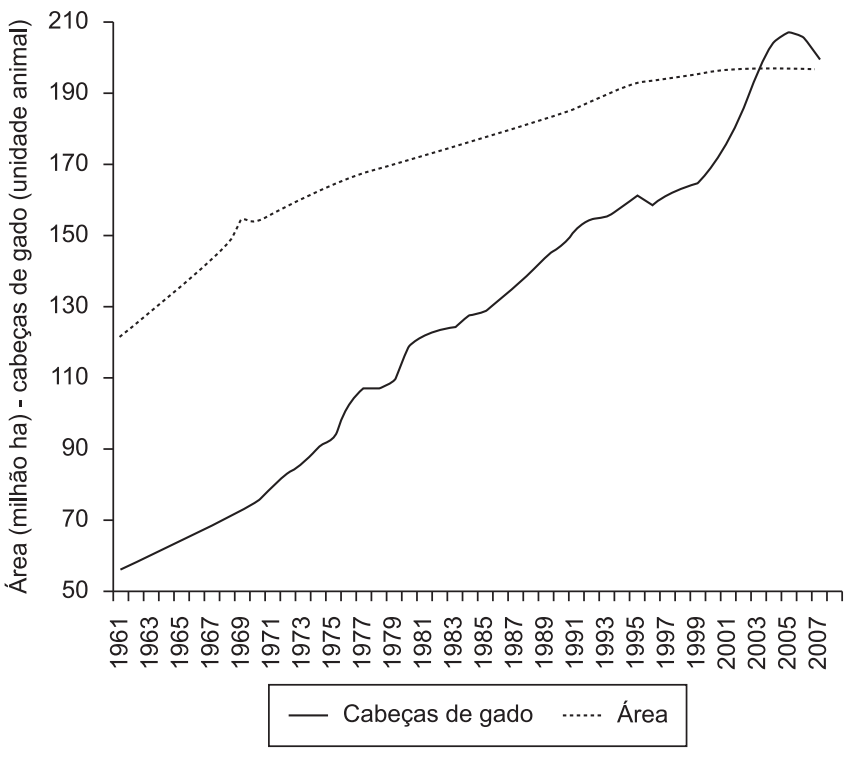

Figura 3. Área (em milhão de ha) ocupada por pastagens e número de cabeças de gado no país.

Figure 3. Area (million ha) of cattle livestock and stocking rates.

estado...) e de mercado, como é o caso do Crédito Fundiário. Portanto, a tendência de concentração da propriedade das terras é constante e intensa; contrabalançando o efeito distributivo da reforma agrária e da natural fragmentação da propriedade rural por herança e partilha de bens. As causas disto incluem a consolidação do mercado agrícola, com a recente onda de transferência da produção agrícola de famílias para corporações e a tradicioanl concepção da terra como reserva patrimonial e não como um dos fatores necessários à produção.

Essa desigualdade apresentada na distribuição de terras não é homogênea quando se examina as diferentes culturas agrícolas do país (Figura 6). Nota-se claramente que a produção arroz, feijão e mandioca é feita principalmente em propriedades até 300 ha (Figura 6). O exemplo mais marcante é o da mandioca, onde mais de $90 \%$ da área colhida desta cultura advém de propriedades com menos de 300 ha (Figura 6). Semelhantemente, $80 \%$ da área colhida com feijão no Brasil também advêm de pequenas e médias propriedades. O inverso ocorre nas culturas da cana e da soja, onde menos de $35 \%$ da área colhida de soja são originadas em pequenas e médias propriedades e menos de $25 \%$ no caso da cana. Nestes casos as grandes propriedades são as maiores responsáveis pela produção (Figura 6).

\section{Discussão}

A análise destes dados indica com clareza que a área colhida de alimentos de consumo direto no mercado nacional como o arroz e o feijão - tem diminuído e a área colhida de mandioca tem se mantido constante há quarenta anos A produtividade da mandioca tem se mantido inalterada por todo este longo período, evidenciando uma falta crônica e antiga de atenção a um dos mais importantes alimentos da dieta nacional (Pastore 1977). A produtividade do feijão e do arroz tiveram aumentos modestos não comparáveis aos aumentos observados nas culturas ligadas à agro-indústria, como a cana-de-açúcar e a soja. Paralelamente, é importante notar que estas duas últimas culturas somaram em 2007 cerca de 27 milhões de ha, ( 20 milhões de ha de soja e 7 milhões de ha de cana) enquanto arroz, feijão e mandioca, juntas, somaram somente cerca 8 milhões de ha.
Assim, conclui-se que a alegação defendida pelo deputado Aldo Rebelo para mudança do Código Florestal, baseada no argumento que falta área para a produção de alimentos não se sustenta frente à análise feita neste estudo. Pois, a área ocupada com alimentos consumidos diretamente pela população tem diminuído e existe uma área significativa ocupada por pastagens ineficientes.

Além de ocupar uma área maior, a produção de soja e cana-deaçúcar concentra-se em grandes propriedades (Figura 6), enquanto a produção de culturas destinadas à alimentação como arroz e, especialmente, mandioca e feijão são produzidas em pequenas e médias propriedades (Figura 6). A industrialização e o destino final da produção diferenciam o segmento dedicado à sua produção.

Apesar de serem importantes produtores de alimento, segundo dados do SIDRA, cerca de $40 \%$ destes pequenos produtores, não obtiveram por diversos motivos financiamento para suas plantações, dentre eles: por não saber como conseguir financiamento, falta de garantia pessoal, medo de contrair dívidas, burocracia e falta de pagamento do empréstimo anteriores. Adicionalmente, segundo a mesma fonte de informação, existem cerca de quase $800 \mathrm{mil}$ proprietários, que somados equivalem a uma área expressiva, que não possuem títulos de suas terras, sendo esta uma fonte importantíssima de insegurança jurídica no meio rural; provavelmente muito mais importante como limitante da produção do que a alegada falta de área para se produzir alimento no país e, consequentemente, induzir mudanças no atual Código Florestal.

Vale ressaltar que o país ainda tem cerca de quase $60 \%$ de sua vegetação nativa preservada e conta com cerca de 250 milhões de ha em áreas agrícolas, incluindo-se a pecuária que sozinha ocupa cerca de 200 milhões de ha. Infelizmente, esta imensa área ocupada pela pecuária é aproveitada de forma pouco intensiva já que a lotação dos pastos brasileiros é baixíssima - cerca de somente uma cabeça por hectare! Esta forma de aproveitamento exige grandes áreas, por consequência muito desmatamento, para se sustentar e crescer. Por comparação, nas áreas mais úmidas dos Estados Unidos a lotação média de pastagens compostas por gramíneas do gênero Cynodon e Paspalum é de quase três animais por hectare (Glen Aiken, USDA, com. pess.).

Como consequência, a área agrícola do país vem continuamente crescendo nas últimas quatro décadas, devido principalmente ao aumento de áreas de pastagens utilizadas de forma extensiva e da expansão da soja e cana-de-açúcar. Estas duas últimas apresentam uma produtividade compatível com as maiores alcançadas no mundo. $\mathrm{Na}$ medida em que estas culturas produtivas avançam e substituem pastagens extensivas acabam gerando uma demanda de expansão da pastagens em áreas de fronteira agrícola, caso já comprovado para a soja (Lapola et al. 2010, Morton et al. 2006, Nepstad et al. 2009). O aumento da lotação das pastagens brasileiras de uma cabeça por hectare para 1,5 cabeças por hectare tornaria disponível para a agricultura o equivalente a 50 milhões de ha, o que corresponde a quase o total da área aproximada ocupada pela agricultura no país. Várias tecnologias simples, de baixo custo e baixo impacto ambiental encontram-se já disponíveis (Cantarutti et al. 2002, Boddey et al. 2004, Pereira et al. 2009), inclusive na região Amazônica, onde a taxa de lotação das pastagens é uma das mais baixas (Rueda et al. 2003). Outra questão é o baixo desfrute do rebanho que é de apenas $22 \%$. Aumentando a lotação para 1,5 cabeças por hectare e o desfrute para $30 \%$ manteríamos o abate anual de 40 milhões de cabeças, e reduziríamos a área de pastagem necessária ainda mais em cerca de 70 milhões de ha.

Assim, é nosso entender que não há falta de área já convertida para a expansão agrícola brasileira, portanto não é verdadeira a dicotomia da preservação versus produção de alimentos. Os maiores entraves para a produção de alimentos no Brasil não se devem a restrições supostamente impostas pelo Código Florestal ou de outra forma de 
Arroz inundado

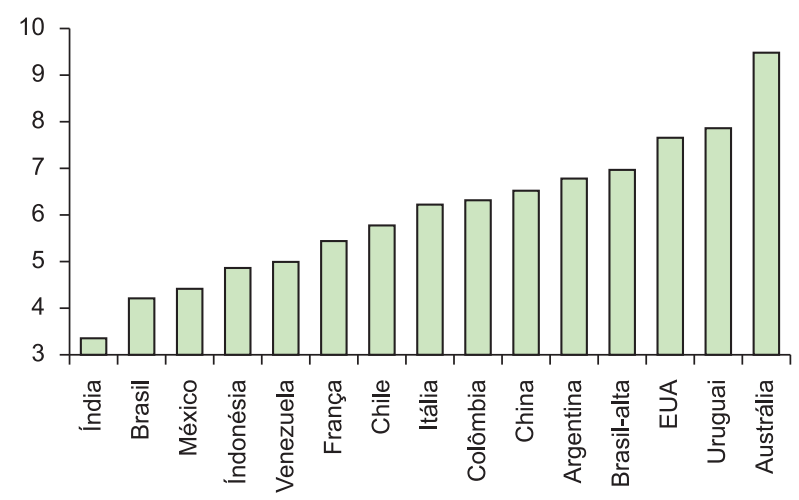

Mandioca

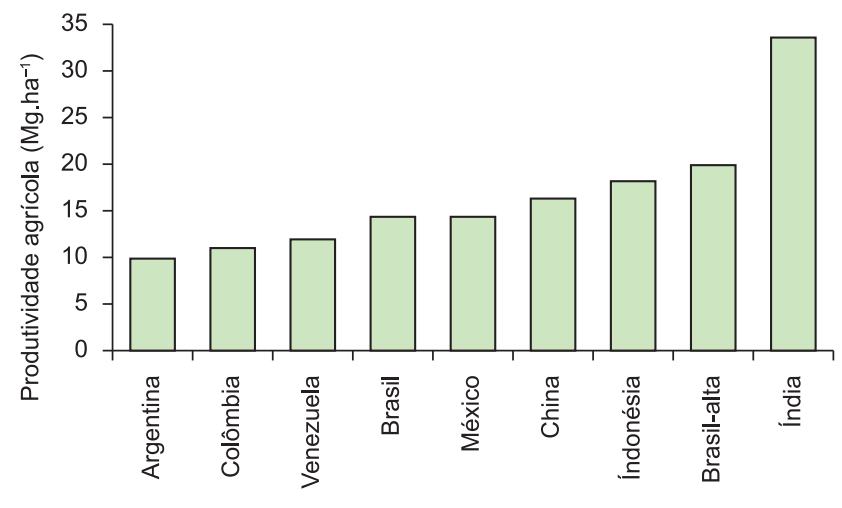

Soja

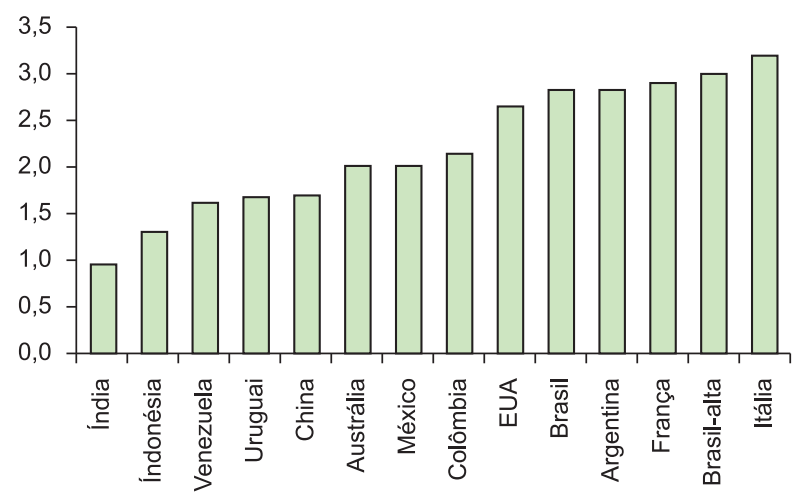

Feijão
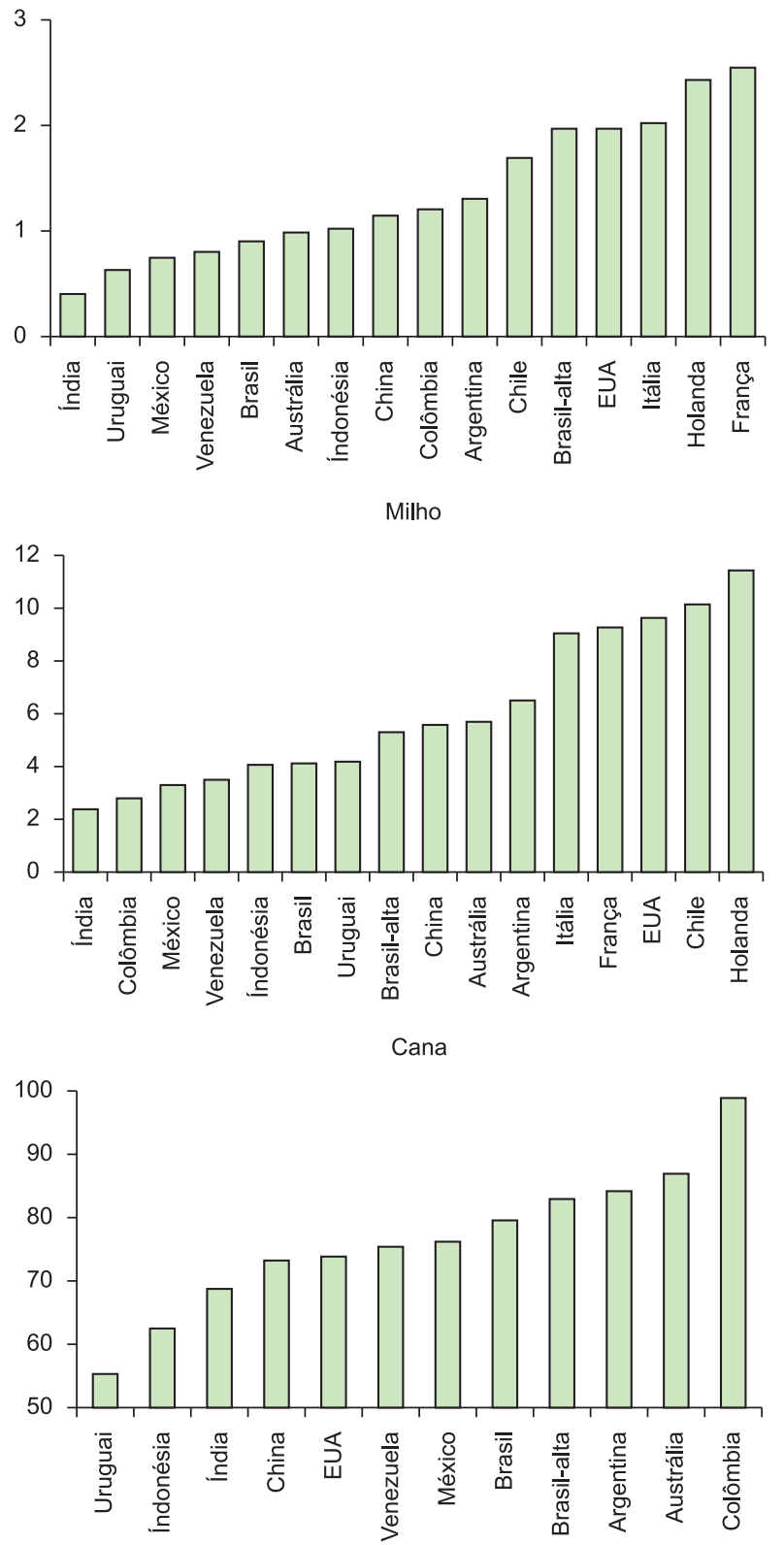

Figura 4. Comparação da produtividade agrícola de algumas culturas entre vários países do mundo. Para o caso específico do Brasil, foram consideradas a produtividade média de todo o país e da região geográfica com maior produtividade média (Brasil-Alta).

Figure 4. Comparison of the productivity among crops cultivated in several countries. For Brazil is was considered the average country productivity and the highest productivity by geographical region (Brasil-Alta).

conservação da vegetação natural, mas, sim, à enorme desigualdade na distribuição de terras, a restrição de crédito agrícola ao agricultor que produz alimentos de consumo direto, a falta de assistência técnica que o ajude a aumentar a sua produtividade, a falta de investimentos em infraestrutura para armazenamento e escoamento da produção agrícola, a restrições de financiamento e priorização do desenvolvimento e tecnologia que permita um aumento expressivo na lotação de nossas pastagens, na pouca ênfase da pesquisa dos setores públicos e privados no aumento da produtividade de itens alimentares importantes para o mercado nacional, e no direcionamento dos investimentos e pesquisas para o modelo industrial da produção agrícola desconsiderando a importância da pequena agricultura tradicional em questões de segurança alimentar, geração e distribuição de renda e ocupações. Em suma, são esses os verdadeiros entraves para a produção de alimentos no Brasil. Assim, como qualquer lei, o Código Florestal pode ser revisto de forma abrangente para se adequar à realidade rural brasileira, mas principalmente, baseando-se também em avanços científicos que podem contribuir no aprimoramento permanente do processo de regulamentação ambiental.

\section{Notas}

${ }^{1}$ Editorial publicado no Jornal Estado de São Paulo em 30/06/2010.

${ }^{2}$ Vinte e sete países compõem a União Europeia de acordo com a definição em www.faostat.org.br. 


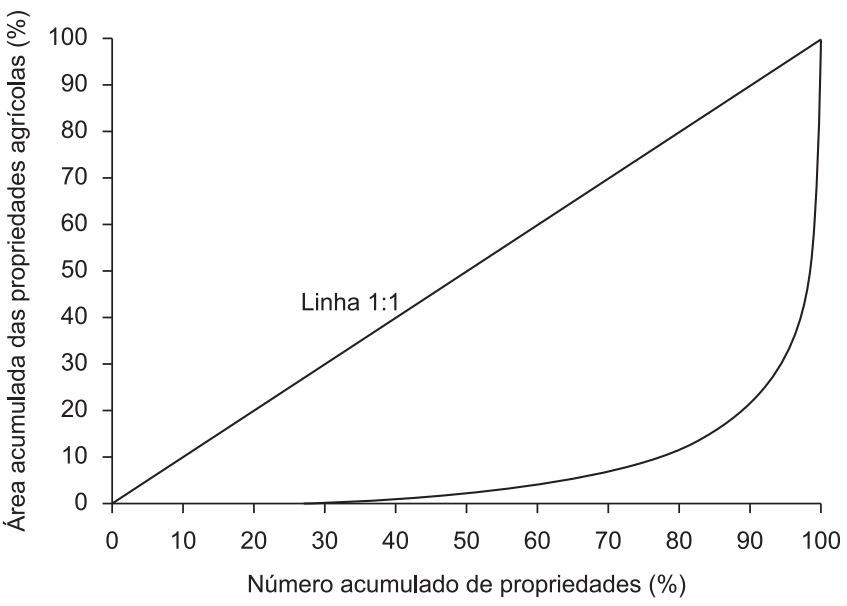

Figura 5. Área acumulada de todas as propriedades rurais do país em percentual versus a área do total de propriedades em ha. A linha mais forte contínua na ordenada indica propriedades com 300 ha, valor que representa aproximadamente quatro módulos fiscais em algumas regiões do país, onde o módulo fiscal é maior. A linha pontilhada na ordenada indica propriedades com 2,500 ha, valor que representa a última classe de área na coleta de dados do SIDRA. Esta classe representa propriedades com, no mínimo, 2,500 ha sem estabelecer o limite máximo.

Figure 5. Percent cumulative area of rural properties in Brazil versus the total area of rural properties expressed in ha. The continuous vertical black line indicates 300 ha-properties, which represents approximately four fiscal rural modules in some regions of the country.

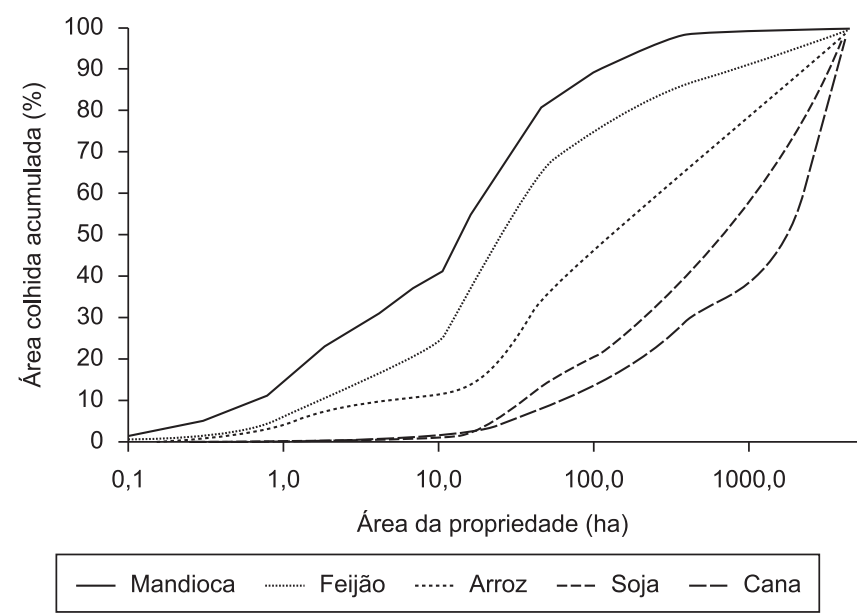

Figura 6. Área colhida acumulada em percentual versus a área das propriedades em ha para as culturas da mandioca, feijão, arroz, soja e cana. A linha mais forte na ordenada indica propriedades com 300 ha, valor que representa aproximadamente quatro módulos fiscais em algumas regiões do país, onde o módulo fiscal é maior. A linha pontilhada na ordenada indica propriedades com 2,500 ha, valor que representa a última classe de área na coleta de dados do SIDRA. Esta classe representa propriedades com, no mínimo, 2,500 ha sem estabelecer o limite máximo.

Figure 6. Percent cumulative area of rural properties in Brazil versus the total area of rural properties expressed in ha for cassava, beans, rice, soybean and sugar cane. The continuous vertical black line indicates 300 ha-properties, which represents approximately four fiscal rural modules in some regions of the country.
${ }^{3}$ Para estimativa de percentuais foram consideradas as seguintes área totais de cada país ou bloco: Brasil - 846 milhões ha; EUA 916 milhões de ha; UE - 418 milhões de ha. Fonte: www.faostat. org.br.

${ }^{4}$ Os autores reconhecem a dificuldade em se comparar a produtividade de culturas agrícolas dentre diferentes países, pois uma série de fatores, como, por exemplo, climáticos, edáficos, genéticos e econômicos, os quais influenciam na produtividade e variam entre países. No entanto, essas comparações são úteis para estabelecer o potencial de aumento em produtividade de uma determinada cultura.

\section{Referências Bibliográficas}

BARROS G. 2008. Brazil: the challenges in becoming an agricultural superpower. In Brazil as an economic superpower? Understanding Brazil's changing role in the global economy (L. Brainard \& L. Martinez-Diaz, ed.). Brookings Institution Press, Washington, D.C., p.2-35.

BODDEY, R.M., MACEDO, R., TARRE, R.M., FERREIRA, E., OLIVEIRA, O.C. \& REZENDE, C.P. 2004. Nitrogen cycling in Brachiaria pastures: the key to understanding the process of pasture decline. Agric. Ecosyst. Environ. 103:389-403.

CANTARUTTI, R.B., TARRE, R., MACEDO, R., CADISCH, G., REZENDE, C.D., PEREIRA, J.M., BRAGA, J.M., GOMIDE, J.A., FERREIRA, E., ALVES, B.J.R., URQUIAGA, S. \& BODDEY, R.M. (2002) The effect of grazing intensity and the presence of a forage legume on nitrogen dynamics in Brachiaria pastures in the Atlantic forest region of the south of Bahia, Brazil. Nutr Cycl Agroecosys 64:257-271.

FAOSTAT. 2010. http://www.faostat.org/ (último acesso em 23/07/2010).

INSTITUTO BRASILEIRO DE GEOGRAFIA E ESTATÍSTICA - IBGE. Sistema IBGE de recuperação automática - SIDRA. 2010. http://www. ibge.br/sidra/ (último acesso em 25/07/2010).

LAPOLA, D.M., SCHALDACH, R., ALCAMO, J., BONDEAU, A., KOCH, J., KOELKING, C. \& PRIESS, J.A. 2010. Indirect land-use changes can overcome carbon savings from biofuels in Brazil. Proc. Natl. Acad. Sci. doi/10.1073/pnas.0907318107.

MORTON, D.C., DEFRIES, R.S., SHIMABUKURO, Y.E., ANDERSON, L.O., ARAI, A., DEL BON ESPIRITO-SANTO, F., FREITAS, R. \& MORISETTE, J. 2006. Cropland expansion changes deforestation dynamics in the Southern Brazilian Amazon. PNAS 103:14637-14641.

NEPSTAD, D., SOARES-FILHO, B., MERRY, F., LIMA, A., MOUTINHO, P., CARTER, J., BOWMAN, M., CATTANEO, A., RODRIGUES, H., SCHWARTZMAN, S., McGRATH, D.G., STICKLER, C.M., LUBOWSKI, R., PIRIS-CABEZAS, P., RIVERO, S., ALENCAR, A., ALMEIDA, O. \& STELLA, O. 2009. The end of deforestation in the Brazilian Amazon. Science 326:1350-1351.

PASTORE, J. 1977. Brazilian agriculture research - export vs nutrition. Food Policy 217-227.

PEREIRA, J.M., TARRE, R.M, MACEDO, R., PAULA REZENDE, C., ALVES, B.J.R., URQUIAGA, S., BODDEY, R.M. 2009. Productivity of Brachiaria humidicola pastures in the Atlantic forest region of Brazil as affected by stocking rate and the presence of a forage legume. Nutrient Cycling in Agroecosystems 83:179-196.

RUEDA, B.L., BLAKE, R.W., NICHOLSON, C.F., FOX, D.G., TEDESCHI, L.O., PELL, A.N., FERNANDES, E.C.M., VALENTIM, J.F. \& CARNEIRO, J.C. 2003. Production and economic potentials of cattle in pasture-based systems of the western Amazon region of Brazil. J. Anim. Sci. 81:2923-2937. 